\title{
INTERSTITIAL PREGNANCY- A CASE REPORT
}

\author{
Geetha Krishnamoorthy1, Thasneem Mohamed Arif ${ }^{2}$
}

${ }_{1}^{1}$ Associate Professor, Department of Obstetrics and Gynaecology, Vinayaka Mission's Medical College, Karaikal, Puducherry. 2Senior Resident, Department of Obstetrics and Gynaecology, Vinayaka Mission's Medical College, Karaikal, Puducherry.

HOW TO CITE THIS ARTICLE: Krishnamoorthy G, Arif TM. Interstitial pregnancy- a case report. J. Evolution Med. Dent. Sci. 2018;7(15): 1923-1924, DOI: 10.14260/jemds/2018/432

\section{PRESENTATION OF CASE}

A 25-year-old lady, G2P1L1 with previous LSCS at 10 weeks of pregnancy came to Vinayaka Mission's Medical College with the chief complaints of bleeding per vaginum of 1 week duration followed by abdominal pain of 3 days' duration which was gradual in onset, spasmodic type and not relieved after taking rest. She was advised USG. It showed normal uterine size with left adnexa showing a mass of size $4 \times 5 \mathrm{cms}$ along with minimal haemoperitonium in the pelvis.

\section{DIFFERENTIAL DIAGNOSES}

1. Intrauterine pregnancy.

2. Chocolate cyst of ovary.

\section{CLINICAL DIAGNOSIS}

On examination, the patient was conscious and oriented. She was not pale and her vitals were stable. On abdominal examination, there was lower abdominal tenderness and left iliac fossa tenderness present. On pelvic examination her uterus was just bulky, cervical motion tenderness present. There was no much vaginal bleeding. In view of severe lower abdominal tenderness and mild tachycardia, ectopic pregnancy was suspected.

\section{DISCUSSION OF MANAGEMENT}

Urine gravindex was positive. Routine investigations were sent, which were normal. She was taken for emergency laparotomy. The intraop findings were left cornual pregnancy with impending rupture of size $5 \times 6 \mathrm{~cm}$. The right cornua of the uterus was normal. The left cornua was resected and repaired and left salpingectomy done. Her postoperative period was uneventful and she was discharged on 5th postoperative day in good condition.

Interstitial pregnancy is a rare form of ectopic pregnancy, but the most hazardous type. In general ectopic pregnancy occurs in $1 \%$ - $2 \%$ of all sexually active reproductive women, of which normal pregnancy accounts for $2 \%-4 \%$. It has $6-7$ times increased mortality rate than others and that $20 \%$ of cases advance beyond 12 weeks of gestation due to its expanding capacity of surrounding musculature which ends in rupture.(1)

Ectopic pregnancy is more common in the ampullary region of the fallopian tube. The part of the tube lying within the musculature of the uterus is called the interstitial/

'Financial or Other Competing Interest': None.

Submission 23-02-2018, Peer Review 21-03-2018,

Acceptance 28-03-2018, Published 09-04-2018.

Corresponding Author:

Dr. Geetha Krishnamoorthy,

18/A, Elaikara Street,

Karaikal-609602,

Puducherry State.

E-mail:vemsrigeenan3@gmail.com

DOI: $10.14260 /$ jemds $/ 2018 / 432$ cornual region. It measures $1-2 \mathrm{~cm}$ with a diameter of $0.7 \mathrm{~mm}$. It is slightly tortuous course extending obliquely upwards and outwards from uterine cavity. (2) The interstitial pregnancy occurs in this site.

An interstitial pregnancy is an uterine but an ectopic pregnancy, as it is located outside the uterine cavity in the part of the fallopian tube penetrating the muscular layer of the uterus. A cornual pregnancy is sometimes used as a synonym.

Interstitial pregnancy should not be confused with angular pregnancy, the latter in which the embryo is implanted in the lateral angle of the uterine cavity. $(2,3)$ Proper diagnosis is mandatory, so as to avoid misdiagnosis of a normal pregnancy which can happen in pregnancy occurring in an anomalous uterus like bicornuate/ septate. However, 3D and 4D transvaginal ultrasound in experienced hand is a valuable tool in making accurate diagnosis in these situations and helps in differentiating between angular and interstitial pregnancies.(3) The diagnosis before rupture is very difficult, as they appear to be in utero on USG. Moreover, due to the distensibility of the myometrium, the foetus tends to grow and rupture late around $7-12$ weeks leading to massive haemorrhage and shock. Hence, the mortality rate is $2 \%$ $2.5 \%$ in interstitial pregnancy than other ectopics.(3)

Interstitial pregnancy poses a great difficulty in early diagnosis as the gestational sac will be seen in an eccentric position, and the adjacent myometrium will be thinned out giving the appearance of an eccentric intrauterine pregnancy. (4)

\section{The USG Criteria are as follows-}

1. Absence of gestational sac in the uterine cavity.

2. Gestational sac seen separately and $<1 \mathrm{~cm}$ taken from the most lateral edge of the uterine cavity.

3. Myometrial layer surrounding the sac would be thin $(<5$ $\mathrm{mm}$ ).

4. "Interstitial line" sign: (Echogenic line extending from the mass to the endometrial echo complex).

During early interstitial gestation, the sac is located in the lateral part of the uterus. Later, the sac may be located above the uterine fundus. $(5,6)$ Thus, interstitial pregnancy detected late appears as an eccentric uterine pregnancy.

Previous PID, previous tubal surgeries like salpingectomy, salpingostomy, previous ectopic pregnancies, ART and congenital uterine anomalies, use of IUCD's, difficulty during embryo transfer procedure, previous history of abortion, endometriosis, rapid transit of fertilised ovum due to nonreceptive endometrium, high number of transfused embryos, excessive pressure on the syringe during the transfer are the possible risk factors for ectopic pregnancies.(6) The clinical presentation of an interstitial pregnancy depends upon whether it is ruptured or not. In unruptured case, patient may present with history of repeated abdominal pain at few days interval or per vaginal bleeding or both. Whereas in ruptured 
case, there will be severe abdominal pain with features of haemodynamic instability.

\section{The Criteria for Conservative Management}

1. Haemodynamic stability.

2. No signs of rupture.

3. Motivated to attend for regular (perhaps prolonged) follow-up.

4. No medical contraindication to methotrexate.

The success rate is $65 \%$ approximately with advantage of preserving the tube and avoiding the surgery.(7) Then the patient is followed by beta hCG in serial levels.

The drug used is methotrexate which can be administered intramuscularly, locally injected transvaginally or USG guided or laparoscopically. Its dose is $1 \mathrm{mg} / \mathrm{m} 2$. Other alternative procedure is selective uterine artery embolisation along with methotrexate or in methotrexate failure cases to decrease the vascularity and prevent the catastrophe.

Surgical management option include laparoscopic cornual resection, cornuotomy, salpingectomy, salpingostomy combined hysteroscopic and laparoscopic USG-guided technique.(8) In ruptured case, laparotomy (i.e.) cornuectomy sometimes it may proceed to hysterectomy.

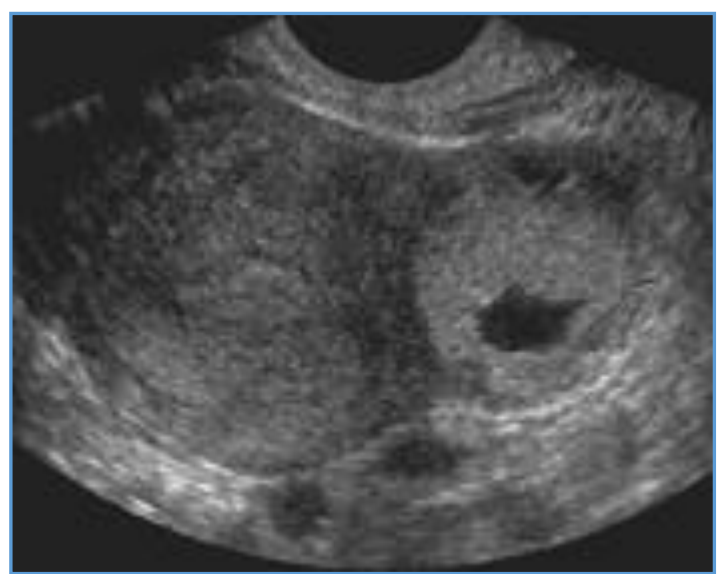

Figure 1. Transvaginal Ultrasound in Transverse Plane showing Interstitial Pregnancy

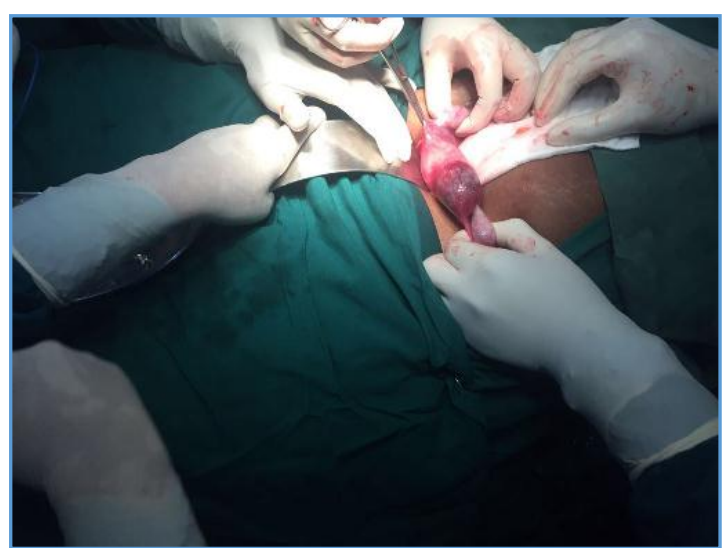

Figure 2. Intra-Op Picture showing Left Interstitial Pregnancy

\section{PATHOLOGICAL DISCUSSION}

Interstitial pregnancy is one of the most important causes of "maternal near miss" case. Interstitial pregnancy with its closeness to both uterine and ovarian branches of uterine artery pose a high surgical risk with potential for massive intraperitoneal bleeding when ruptured. Hence, early diagnosis using USG and prompt treatment is the cornerstone in reducing the mortality and morbidity for ectopic.(9)

In our case as the diagnosis was made earlier, so the catastrophe of the ruptured uterus and massive haemorrhage was avoided. She was taken for emergency laparotomycornuectomy with left salpingectomy. Specimen was sent for biopsy, which confirmed the presence of chorionic villi.

\section{FINAL DIAGNOSIS}

Clinical examination and perop finding concluded the final diagnosis of unruptured interstitial pregnancy.

\section{REFERENCES}

[1] Alam IP. Cornual pregnancy: a case report. Faridpur Med Coll J 2013;8(2):102-4.

[2] Surekha SM, Chamaraja T, Singh NN, et al. A ruptured left cornual pregnancy: a case report. Journal of Clinical of Diagnostic Research 2013;7(7):1455-6.

[3] Velayudam DA, Prabhu RBT, Devi DL, et al. Recurrent cornual ectopic pregnancy: a case report. Int J Med Res Health Sci 2015;4(4):919-20.

[4] Chandran JR. Cornual pregnancy and its management: a case report. IJSS Case Report \& Reviews 2014;1(6):13.

[5] Shetty M, Shivananjaiah C, Swarup A, et al. A rare case report of cornual pregnancy. Obstet Gynaecology Int J 2016;5(6):00179.

[6] Atal R, Chauhan M. A rare case report of ruptured cornual ectopic pregnancy. IJOGR 2016;3:400-4.

[7] Al-Ibrahim N. Intact left cornual ectopic pregnancy: a case report. Oman Medical Journal 2013;28:4.

[8] Kingsley OV, Solomon N, Vitalis I. Cornual twin ectopic pregnancy: a case report. Article 1 no JAMMR: 34186. JAMMR 2017;22(9):1-5.

[9] Alagbe OA, Adeniyi TO, Abayomi OA, et al. Interestitial ectopic pregnancy: a case report. The Pan African Medical Journal 2017;28:135. 